Jambura Physics Journal
$\begin{gathered}\text { p-ISSN: 2654-9107 e-ISSN: } 2721-5687 \\ \text { Journal homepage: http://ejurnal.ung.ac.id/index.php/JPJ }\end{gathered}$

\title{
PENGEMBANGAN PERANGKAT PEMBELAJARAN IPA SMP MENGGUNAKAN MODEL PEMBELAJARAN KOOPERATIF TIPE STUDENT TEAMS ACHIEVEMENT DIVISIONS (STAD) BAGI SISWA BERKEBUTUHAN KHUSUS
}

\author{
Fandi Mamonto ${ }^{*}$, Masri Kudrat Umar2, Dewi Diana Paramata ${ }^{3}$ \\ 1,2,3 Jurusan Fisika, Universitas Negeri Gorontalo, Jl. Jendral Sudirman Kota Gorontalo 96128, Indonesia \\ Email: fandimamonto23@gmail.com
}

Received: 20 November 2020. Accepted: 27 April 2021. Published: 30 April 2021

\section{ARTICLE INFO}

\section{Keywords: \\ Learning tools; STAD; students with special needs}

\section{How to cite:}

Mamonto, F., Umar, M.K \& Paramata, D.D. (2021). Pengembangan Perangkat Pembelajaran IPA SMP Menggunakan Model Pembelajaran Kooperatif Tipe Student Achievement Divisions (STAD) Bagi Siswa Berkebutuhan Khusus. Jambura Physics Journal, 3(1), 54-63

\section{DOI:}

https://doi.org/10.34312 /jpj.v3i1.8137

\begin{abstract}
This study aims to produce a science learning device for junior high school students using a cooperative model type Student Teams Achievement Divisions (STAD) for students with special needs that are valid and fit for use theoretically. The research method used is the development of the $4 \mathrm{D}$ model design through 4 stages including the defining stage, the design stage, the development stage, and the dissemination stage. The technique of collecting data through validation sheets consists of lecturers, science teachers, school principals, and students. Based on the research results, the validity of the equipment was obtained through the Aiken $\mathrm{V}$ index in the RPP of 0.89 , LKPD of 0.88 , and THB of 0.88 . The three components of the device are considered very valid criteria. The reliability test of each component for RPP is 0.818 , LKPD is worth. 0.857 , and THB worth 0.884 . The components of learning equipment are reliable with good categories based on the Interrater Correlation Coefficient (ICC). Theoretically, the learning tools developed are valid and feasible to be tested in class VIII of the Gorontalo City Learning Activity Center (SKB).
\end{abstract}


Mamonto, F., et al. / Jambura Physics Journal (2021) Vol. 3 (1): 54-63

\section{Pendahuluan}

Siswa berkebutuhan khusus sebagai seseorang yang memiliki karakter berbeda dengan siswa lainnya yang dipandang normal oleh masyarakat pada biasanya. Lebih khusus siswa dengan keterbatasan menonjolkan sebuah karakteristik emosional, fisik, serta intelektual yang berbeda dari siswa sebyanya atau dikatakan berada pada luar standar normal yang saat ini berlaku di tatanan hidup bermasyarakat sehingga sedikit mengalami sebuah kesulitan dilihat dari segi aktivitas, sosial dan personal dalam bidang pendidikan (Bachri, 2010).

Hasil observasi awal di SKB Kota Gorontalo pada jenjang SMP kelas VIII, proses pembelajaran berlangsung belum efisien terutama dalam proses pembelajaran IPA. Masih banyak siswa ketika dalam suasana pembelajaran masih sering bermain di dalam kelas, kurang fokus dengan apa yang dijelaskan oleh guru, motivasi untuk belajar tergolong rendah dan sulit untuk memahami materi terlebih dengan materi yang mereka anggap sulit dan membosankan.

Bercermin dari dari permasalahan yang terdapat di SKB Kota Gorontalo perlu adanya suatu terobosan dalam hal pengajaran. Oleh karena itu, perlu adanya suatu perangkat pembelajaran yang menunut pendidik untuk lebih mempersiapkan diri sebelum melakukan proses kegiatan belajar mengajar. Pengembangan perangkat ialah suatu lingkaran yang berkelanjutan. Tiap tahapan pengembangan perangkat dimulai dari prosedur yang ada di sekolah dan disesuaikan dengan pedoman yang berlaku (Trianto, 2007).

Belajar IPA memerlukan keterampilan dari seorang guru agar anak didik mudah memahami materi yang diberikan guru. terlebih lagi siswa yang dihadapi adalah siswa berkebutuhan khusus. Jika guru kurang menguasai strategi mengajar maka siswa akan sulit menerima materi pelajaran dengan sempurna (Santoso \& Rianto, 2013). Guru dituntut untuk mengadakan inovasi dan berkreasi dalam melaksanakan pembelajaran, sehingga hasil belajar siswa memuaskan. IPA khususnya fisika merupakan pelajaran sangat dibutuhkan karena berhubungan langsung dengan kehidupan sehari-hari. Mengingat pentingnya peranan IPA tersebut, maka hasil belajar di sekolah perlu mendapat perhatian yang sungguh-sungguh dari semua pihak yang terkait.

Disadari bahwa setiap siswa memiliki kemampuan yang berbeda-beda dalam menerima pelajaran yang dijelaskan oleh guru. Upaya untuk dapat meminimalkan perbedaaan tersebut, maka dibentuk secara berkelompok agar siswa dapat saling mengisi, saling melengkapi, serta bekerja sama dalam menyelesaikan soal-soal atau tugas yang diberikan oleh guru. Demikian tujuan pengajaran dapat tercapai dan hasil belajar siswapun dapat ditingkatkan (Rahayuningsih, 2018).

Model pembelajaran kooperatif tipe STAD memungkinkan guru dapat memberikan perhatian terhadap siswa. Hubungan yang lebih akrab akan terjadi antara guru dengan siswa maupun antara siswa dengan siswa (Setiogohadi, 2014 dan Nuayi et.al, 2018). Adakalanya siswa lebih mudah belajar dari temannya sendiri, adapula siswa yang lebih mudah belajar karena harus mengajari atau melatih temannya sendiri. Dalam hal ini model pembelajaran kooperatif tipe STAD dalam pelaksanaannya mengacu kepada belajar kelompok siswa. Untuk memenuhi kebutuhan tersebut dan memungkinkan siswa belajar lebih aktif, mempunyai rasa 
Mamonto, F., et al. / Jambura Physics Journal (2021) Vol. 3 (1): 54-63

tanggung jawab yang besar, berkembangnya daya kreatif, serta dapat memenuhi kebutuhan siswa secara optimal.

Kooperatif tipe Student Teams Achievement Divisions (STAD) ialah pembelajaran kooperatif terdapat beberapa kelompok kecil siswa dengan level kemampuan kognitif yang berbeda satu sama lain dengan tujuan untuk menyelesaikan suatu permasalahan (Subrata, 2016). Menggunakan model kooperatif tipe STAD pengoptimalan siswa dalam berpartisipasi dan mengeluarkan pendapat mampu tergambarkan dalam model ini, sehingga siswa lebih mudah memahami maksud dari materi yang diajarkan serta peranan siswa akan lebih aktif dalam pembelajaran dan pendidik tidak hanya menjadi pusat pemberian informasi tetapi hanya sebagai pembimbing bagi siswa (Huda, 2013).

Pembelajaran berlandaskan model tipe STAD dapat mendorong siswa untuk lebih berpartisipasi aktif, mempunyai rasa tanggung jawab yang besar, bekembangnya pengetahuan yang dapat memenuhi ilmu pengetahuan secara optimal dengan penerapan STAD guru memungkinkan dapat memberi perhatian untuk siswa. Interaksi yang baik akan tercipta antara pendidik dan siswa maupun sesama siswa. Disisi lain terdapat siswa dengan mudahnya memahami penejelasan teman dibandingkan penjelasan guru. Model STAD mengacu dalam penerapannya mengacu pada kelompok belajar (Haryanto, dkk, 2015).

Langkah dari pembelajaran model kooperatif tipe Student Teams Achievement Divisions atau STAD terdiri dari beberapa tahapan, diantaranya: (1) Menginformasikan tujuan pembelajaran dan memotivasi siswa, termasuk manyampaikan KD dan tujuan yang ingin dicapai serta pemberian apersepsi pada siswa. (2) Pendidik mengarahkan siswa dalam bentuk kelompok terdiri atas 3-4 siswa perkelompoknya. (3) Memberi informasi. Tugas dari guru di tahap ini untuk menyajikan informasi berupa konsep pembelajaran dan tata cara sebelum melakukan pembelajaran. (4) Pendidik melaksanakan pemberian pekerjaan kepada siswa berupa soal yang ada di LKPD untuk dikerjakan siswa secara berkelompok. (5) Siswa yang mudah memahami materi dapat menjelaskan kepada teman sekelompok sampai keseluruhan individu dalam kelompok tersebut paham (Kurniasih \& Sani, 2015).

\section{Metode}

\subsection{Jenis Penelitian}

Penelitian ini termasuk dalam penelitian pengembangan atau Research and Development (R\&D) dengan menggunakan desain model pengembangan 4D yang terdiri 4 tahap yaitu pendefinisian (define), perancangan (design), pengembangan (development), dan penyebaran (dissemination) (Thiagarajan, 1974). Penelitian ini menghasilkan produk perangkat pembelajaran IPA SMP menggunakan model pembelajaran kooperatif tipe STAD meliputi Rencana Pelaksanaan Pembelajaran (RPP), Lembar Kerja Peserta Didik (LKPD) dan Tes Hasil Belajar (THB) bagi siswa berkebutuhan khusus pada konsep materi tekanan zat dan penerapan dalam kehidupan sehari-hari.

Penelitian ini dilaksanakan di Sanggar Kegiatan Belajar (SKB) Kota Gorontalo pada jenjang SMP Kelas VIII yang beralamat di Jl. Prof Dr. John Ario Katili, Kelurahan Tapa, Kecamatan Sipatana Kota Gorontalo. Penelitian ini dilaksanakan selama 4 bulan. 
Mamonto, F., et al. / Jambura Physics Journal (2021) Vol. 3 (1): 54-63

2.2 Rancangan penelitian

Rancangan penelitian ini menggunakan desain model 4D (Four-D) yang terdiri dari 4 tahap pengembangan di modifikasi berupa penyederhanaan model dari empat tahap menjadi tiga tahap, yaitu pendefinisian (define), perancangan (design), dan pengembangan (develop). Namun, dalam penelitian ini hanyasampai pada tahap pengembangan dengan meniadakan uji coba produk dan tahap penyebaran

\subsection{Instrumen pengumpulan data}

Lembar validasi merupakan format yang berisi komponen-komponen penliaian dari validator ahli yang memuat nilai yang akan diberikan terhadap perangkat pembelajaran yang telah dikembangkan (Sujadi, 2003). Dalam penelitian ini, lembar validasi yang gunakan berupa lembar validasi rencana pelaksanaan pembelajaran (RPP), lembar validasi lembar kerja peserta didik (LKPD) dan lembar validasi tes hasil belajar. Lembar Validasi terdiri dari beberapa aspek penilaian yang telah dikembangkan oleh peneliti dan terdiri dari beberapa indikator yang berfungsi untuk menilai kevalidan dan kelayakan perangkat yang dinilai oleh validator ahli dengan memberi nilai dalam skala 1-5.

\subsection{Teknik analisis data}

\section{Kevalidan Perangkat Pembelajaran}

Perhitungan kevalidan dari perangkat pembelajaran diperoleh dari lembar validasi perangkat pembelajaran kemudian dianalisis dengan menggunakan koefisien Aiken $\mathrm{V}$ untuk menguji validitas dari tiap komponen perangkat pembelajaran menggunakan rumus:

$$
\mathrm{V}=\frac{\sum \mathrm{s}(\mathrm{r}-\mathrm{lo})}{[\mathrm{n}(\mathrm{c}-1)]} \times 100 \%
$$

Keterangan:

$\mathrm{V}=$ Rata-rata keseluruhan validasi

$\Sigma \mathrm{s}=$ Jumlah pengurangan nilai rater dikurangi nilai terendah

$\mathrm{r} \quad=$ angka yang diberikan oleh penilai

lo = angka penilaian validitas terendah

$\mathrm{c} \quad=$ angka penilaian validitas yang tertinggi

$\mathrm{n}$ = banyaknya penilai/validator

Kemudian pada setiap komponen perangkat pembelajaran dianalisis lalu ditafsirkan dalam bentuk kualitatif untuk mengetahui kevalidan dan kelayakan dari produk berupa perangkat pembelajaran yang sudah dikembangkan. Adapun kriteria kevalidan perangkat pembelajaran diapat dilihat pada tabel 1 berikut ini.

Tabel 1. Kriteria Kevalidan Perangkat Pembelajaran

\begin{tabular}{ll}
\hline Rata-rata Indeks & Kriteria Validasi \\
\hline $\mathrm{V}>0.8$ & Sangat Valid \\
$0.4 \leq \mathrm{V} \leq 0.8$ & Valid \\
$\mathrm{V}<0.4$ & Kurang Valid \\
\hline
\end{tabular}

Uji Reliabilitas Perangkat Pembelajaran

Pengujian reliabilitas dari perangkat pembelajaran menggunakan tingkat kesepakatan antar penilai (Expert Judgment) bertujuan untuk menghitung reliabilitas penilaian dari masing-masing komponen perangkat pembelajaran menggunakan Interclass Corelation Coeffisient (ICC). Pengujian reliabilitas menggunakan bantuan 
Mamonto, F., et al. / Jambura Physics Journal (2021) Vol. 3 (1): 54-63

aplikasi SPSS 16.0. Estimasi untuk mengetahui tingkat reliabilitas menggunakan pendekatan dengan kriteria reliabilitas instrumen menurut George Mallery disajikan data seperti pada tabel 2 berikut.

Tabel 2. Interpretasi Reliabilitas Interclass Corelation Coeffisient (ICC).

\begin{tabular}{ll}
\hline Reliabilitas & Kriteria Reliabilitas \\
\hline $0.9-1.00$ & Luar Biasa \\
$0.8-0.89$ & Baik \\
$0.7-0.79$ & Dapat diterima \\
$0.6-0.69$ & Dipertanyakan \\
$0.5-0.59$ & Rendah \\
$0.0-0.49$ & Tidak Bisa Diterima \\
\hline & (Sugiyono, 2011)
\end{tabular}

\section{Hasil dan Pembahasan}

\subsection{Hasil Kevalidan Perangkat Pembelajaran}

Rencana Pelaksanaan Pembelajaran (RPP)

Penilaian rater terhadap RPP awal yang dikembangkan sebelum direvisi (Draft I) menggunakan model pembelajaran kooperatif tipe STAD mengacu pada butir-butir indikator pada setiap aspek penilaian. Kevalidan RPP menggambarkan valid atau tidakkah RPP yang dikembangkan sebelum dilanjutkan pada tahap ujicoba terbatas. Terlebih dahulu diuji Content Validity maka hasil yang diperoleh dari rater/validator dapat dilihat pada tabel 3.

Tabel 3. Kevalidan Rencana Pelaksanaan Pembelajaran (RPP)

\begin{tabular}{clc}
\hline Indikator & Item & Rata-rata validasi \\
\hline 1 & Satuan pendidikan & 0.88 \\
2 & Materi & 0.97 \\
3 & Alokasi waktu & 0.86 \\
4 & Kelengkapan cakupan rumusan kompetensi inti (KI) & 0.83 \\
& & \\
5 & Kelengkapan cakupan rumusan kompetensi dasar (KD) & 0.89 \\
& & 0.88 \\
7 & Kejelasan Indikator & 0.92 \\
7 & Kesesuaian indikator dengankompetensi dasar (KD) & 0.87 \\
9 & Kesesuaian dengan Indikator & 0.86 \\
10 & Kesesuaian dengan karakteristik perseta didik & 0.86 \\
11 & Keruntutan dan sistematika materi & 0.92 \\
12 & Kesesuaian materi dengan alokasi waktu & 0.92 \\
13 & denganpilkan pendahuluan, kegiatan inti, dan penutup & 0.92 \\
14 & Pendahuluan & 0.89 \\
15 & Kegiatan inti & 0.86 \\
\hline
\end{tabular}


Mamonto, F., et al. / Jambura Physics Journal (2021) Vol. 3 (1): 54-63

\begin{tabular}{clc}
\hline 16 & $\begin{array}{l}\text { Kesesuaian kegiatan inti dengan model pembelajaran } \\
\text { dan materi pembelajaran }\end{array}$ & 0.87 \\
17 & Penutup & 0.97 \\
\hline & V (Rata-rata Keseluruhan) & 0.89 \\
& Kategori & Sangat Valid \\
\hline
\end{tabular}

Melihat hasil yang disajikan pada tabel 3, pada keseluruhan butir indikator penilaian RPP memperoleh indeks terendah sebesar 0,83 dan indeks tertinggi 0.97 . Rata-rata keseluruhan tingkat validitas kesepakatan antar penilai memperoleh hasil sebesar 0.879 . Sehingga dapat di interpretasikan secara teoritis bahwa validitas RPP yang telah dikembangkan termasuk ke dalam kategori sangat valid berdasarkan indeks Aiken ( $\mathrm{V}>0.8)$.

Lembar Kerja Peserta Didik (LKPD)

LKPD telah dikembangkan sebelumnya kemudian dinilai oleh rater atau validator ahli guna mengetahui validitas berdasarkan kesepakatan antar rater/penilai terhadap LKPD pada Draft I (awal). Kevalidan dari LKPD mengacu pada indikator penilaian. Validitas LKPD yang diperoleh melalui validator terdapat pada tabel di bawah ini.

Tabel 4. Kevalidan Lembar Kerja Peserta Didik (LKPD)

\begin{tabular}{|c|c|c|}
\hline Indikator & Item & Rata-rata validasi \\
\hline 1 & $\begin{array}{l}\text { Kesesuaian materi dengan Indikator dan Tujuan } \\
\text { pembelajaran }\end{array}$ & 0.82 \\
\hline 2 & Pertanyaan mendukung materi & 0.88 \\
\hline 3 & $\begin{array}{l}\text { Memiliki petunjuk untuk siswa mengenai topik yang } \\
\text { akan dibahas }\end{array}$ & 0.92 \\
\hline 4 & Prosedur kerja ditulis secara jelas dan berurutan & 0.91 \\
\hline 5 & $\begin{array}{l}\text { Kedalaman materi sesuai dengan karakteristik peserta } \\
\text { didik }\end{array}$ & 0.88 \\
\hline 6 & $\begin{array}{l}\text { Menggunakan kalimat sederhana, jelas dan mudah } \\
\text { dipahami }\end{array}$ & 0.83 \\
\hline 7 & Kejelasan petunjuk LKPD & 0.94 \\
\hline 8 & $\begin{array}{l}\text { Kegiatan dalam LKPD dapat membantu siswa dalam } \\
\text { memahami materi }\end{array}$ & 0.89 \\
\hline & V (Rata-rata Keseluruhan) & 0.88 \\
\hline & Kategori & Sangat Valid \\
\hline
\end{tabular}

Berdasarkan hasil yang disajikan pada tabel 4, dari seluruh butir indikator penilaian LKPD memperoleh indeks terendah sebesar 0.82 terdapat pada butir 1 dan indeks tertinggi 0.94 terdapat pada butir 7. Rata-rata keseluruhan tingkat validitas kesepakatan antar penilai terhadap LKPD memperoleh hasil sebesar 0.88. Menurut indeks Aiken dapat di interpretasikan bahwa LKPD yang dikembangkan termasuk ke dalam kategori sangat valid $(\mathrm{V}>0.8)$ berdasarkan kesepakatan penilaian rater.

Tes Hasil Belajar (THB)

Validitas dari Tes Hasil Belajar diperoleh berdasarkan nilai yang didapat melalui rater/penilai dengan berpedoman pada setiap butir indikator penilaian yang 
Mamonto, F., et al. / Jambura Physics Journal (2021) Vol. 3 (1): 54-63

menyangkut tentang materi pembelajaran, serta kriteria kognitif siswa. Hasil validitas tes hasil belajar dapat dilihat pada tabel berikut ini.

Tabel 5. Kevalidan Tes Hasil Belajar (THB)

\begin{tabular}{|c|c|c|}
\hline Indikator & Item & Rata-rata validasi \\
\hline 1 & Batasan soal dirumuskan dengan jelas & 0.87 \\
\hline 2 & Jawaban yang diharapkan jelas & 0.79 \\
\hline 3 & $\begin{array}{l}\text { Instrumen soal sesuai dengan tujuan pembelajaran } \\
\text { yang harus dicapai oleh peserta didik }\end{array}$ & 0.9 \\
\hline 4 & $\begin{array}{l}\text { Isi pertanyaan menggunakan kata-kata yang mudah } \\
\text { dipahami }\end{array}$ & 0.89 \\
\hline 5 & $\begin{array}{l}\text { Rumusan pertanyaan/soal menggunakan kalimat } \\
\text { tanya atau perintah yang jelas }\end{array}$ & 0.93 \\
\hline 6 & $\begin{array}{l}\text { Menggunakan struktur kalimat yang sesuai dengan } \\
\text { kaidah bahasa indonesia yang baik dan benar }\end{array}$ & 0.9 \\
\hline 7 & $\begin{array}{l}\text { Kalimat soal/pertanyaan tidak mengandung arti } \\
\text { Ganda }\end{array}$ & 0.85 \\
\hline & V (Rata-rata keseluruhan) & 0.88 \\
\hline & Kategori & Sangat Valid \\
\hline
\end{tabular}

Berdasarkan hasil yang disajikan pada tabel 5, pada seluruh butir indikator penilaian THBmendapat indeks terendah sebesar 0.79 terdapat dalam butir 2 dan indeks tertinggi 0.93 terdapat dalam butir 5. Diperoleh rata-rata validitas dari rater/penilai mendapat hasil sebesar 0.88 . Diinterpretasikan secara teoritis menurut Indeks Aiken bahwa tes hasil belajar yang dikembangkan tergolong kedalam kategori sangat valid $(\mathrm{V}>0.88)$ berdasarkan nilai dari kesepakatan rater. Kevalidan dari tiap komponen perangkat pembelajaran menggunakan model pembelajaran kooperatif tipe STAD yang diperoleh dari para rater/penilai dapat dilihat pada diagram berikut ini.

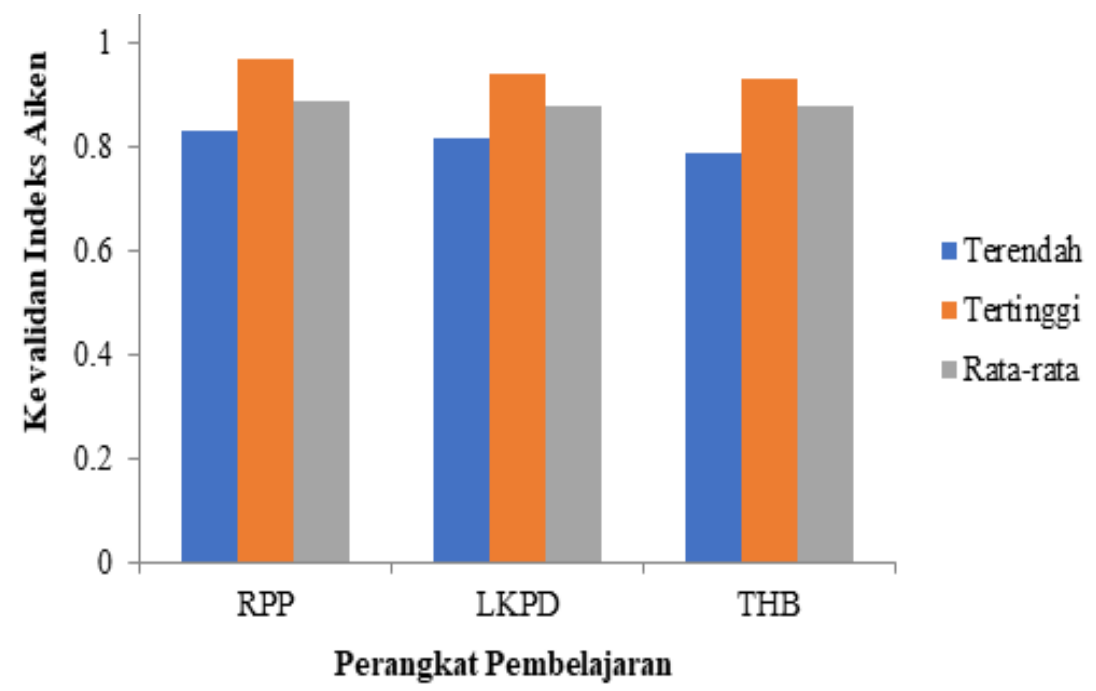

Gambar 1. Kevalidan Perangkat Pembelajaran

Berdasarkan data kevalidan pada setiap komponen perangkat pembelajaran menjukkan adanya selisih yang tidak cukup jauh antara indeks terendah dan tertinggi pada masing-masing komponen perangkat serta menunjukkan adanya kekonsistenan 
Mamonto, F., et al. / Jambura Physics Journal (2021) Vol. 3 (1): 54-63

tingkat kevalidan yang diberikan oleh para rater/penilai sehingga dapat dikategorikan sangat valid secara teoritis.

Siswa yang ditemui di lapangan memiliki beragam karakteristik serta tipe kebutuhan. Temuan berdasarkan hasil pengamatan dan observasi diperoleh siswa dengan karakteristik Slow Learner (lamban belajar), siswa dengan emosional dan sikap yang tidak wajar (tunalaras), siswa pendiam, dan siswa yang mengalami kesulitan belajar. Beragam tipe tersebut membuat guru lebih ekstra dalam mengajar agar siswa mampu secara mental dalam menerima materi.

Perangkat pembelajaran yang dikembangkan berlandaskan atas sintaks model pembelajaran kooperatif tipe STAD sebagaimana (Wibowo, 2016 dan Nuayi et.al, 2018)). Langkah-langkah penerapan dalam model pembelajaran kooperatif tipe STAD terdiri dari 6 langkah diantaranya: (1) menyampaikan tujuan pembelajaran, (2) menyampaikan materi, (3) berdiskusi dalam kelompok, (4) pemberian kuis/pertanyaan, (5) penyimpulan, (6) pemberian penghargaan. Produk yang telah dirancang pada Draft I (Perangkat awal) berupa RPP, LKPD, dan THB memuat konsep materi tekanan zat dan penerapannya dalam kehidupan sehari-hari.

Kevalidan perangkat pembelajaran dari hasil validasi oleh 30 validator ahli, menunjukkan bahwa ketiga komponen perangkat yang sudah dikembangkan menggunakan model kooperatif tipe STAD memenuhi kriteria sangat valid secara teoritik. Melalui analisis data Aiken V memperoleh rata-rata kevalidan RPP sebesar 0.899 serta LKPD dan THB sebesar 0.88. Untuk indeks aiken terendah pada masingmasing item di setiap komponen perangkat menjadi pertimbangan untuk memperbaiki dokumen dengan memperhatikan saran dan masukan dari para validator.

Sebagaimana penelitian terdahulu (Ulfah, 2016) dengan judul Pengembangan Tes Kemampuan Berpikir Kritis Peserta Didik Pada Materi Hukum Newton Di SMP. Pembuktian kevalidan ini ditentukan melalui kesepakatan ahli menggunakan Indeks Aiken V. Kevalidan penelitian ini dilakukan oleh 4 orang ahli oleh yaitu 2 orang dosen Fisika FKIP UNTAN dan 2 orang guru mata pelajaran IPA di SMP Negeri 3 Sungai Raya Kabupaten Bengkayang. Dari hasil validasi isi yang dilakukan oleh keempat ahli memperoleh nilai sebesar 0,734 termasuk kategori valid. Sehingga dapat disimpulkan dapat dilaksanakan sampai pada tahap ujicoba produk.

\subsection{Hasil Uji Reliabilitas Perangkat Pembelajaran}

Pengujian reliabilitas untuk melihat kesepakatan rater/penilai Interrater correlation coefficient (ICC) agar dapat mengetahui sejauh mana konsistensi antara penilai terhadap setiap komponen perangkat pembelajaran yang telah dikembangkan. Adapun hasil analisis data pengujian reliabilitas dapat dilihat pada tabel berikut 6 ini.

Tabel 6. Hasil Reliabilitas Perangkat Pembelajaran

\begin{tabular}{ll}
\hline Perangkat Pembelajaran & ICC \\
\hline Rencana Pelaksanaan Pembelajaran (RPP) & 0.818 \\
Lembar Kerja Peserta Didik (LKPD) & 0.857 \\
Tes Hasil Belajar (THB) & 0.884 \\
\hline
\end{tabular}


Berdasarkan tabel 6, menunjukkan bahwa reliabilitas dari ketiga komponen perangkat, menggunakan Interclass Corelation Coefficient (ICC) atau reliabilitas antar penilai. Menurut George dan Mallery (2009) reliabilitasnya termasuk kedalam kategori baik (Koefisien reliabilitas ICC berkisar antara 0.8-0.89). Reliabilitas menunjukkan bahwa tidak terdapat perbedaan yang signifikan terhadap penilaian antarrater, diperoleh tingkat kesepakatan (reliabilitas) penilaian ahli untuk RPP senilai 0.818 , LKPD senilai 0.857 dan THB senilai 0.884 .

Pengujian reliabilitas menggunakan reliabilitas antar rater/penilai (Interrater Corellation Coeffisient) atau disebut juga ICC. Reliabilitas ICC yang dihasilkan berdasarkan penilaian para rater memenuhi kriteria baik, dapat dilihat pada kesepakatan rater untuk RPP memperoleh 0.818, LKPD sebesar 0.857 dan THB dengan nilai 0.884. Melihat dari hasil penelitian dari (Iskandar, 2015) penelitian berjudul Pengembangan Perangkat Penilaian Psikomotor Di Sekolah Menengah Kejuruan. Pada pengujian reliabilitas Lembar penilaian psikomotor dalam kegiatan praktikum berada pada rentang "Baik", dilihat keseluruhan lembar penilaian ini dinyatakan memenuhi kriteria valid dan koefisien reliabilitas dari beberapa penilai (Intraclass Correlation Coefficients, ICC) sebesar 0.718. Nilai koefisien reliabilitas instrumen ini termasuk kategori good agreement, sehingga instrumen tersebut memenuhi kriteria reliabel.

Kriteria reliabilitas ICC secara teoritis dapat ditafsirkan ketiga komponen tersebut termasuk kriteria baik. Dengan demikian, perangkat pembelajaran yang telah dikembangkan menggunakan model kooperatif tipe STAD bagi siswa berkebutuhan khusus secara teori dikatakan valid dan reliabel sehingga dapat dilakukan ke dalam tahap uji coba terbatas sebagai penelitian lebih lanjut oleh peneliti lainnya di SKB Kota Gorontalo.

\section{Kesimpulan}

Berdasarkan hasil penelitian serta analisis data, dapat disimpulkan bahwa perangkat pembelajaran IPA SMP menggunakan model kooperatif tipe Student Teams Achievement Divisions (STAD) bagi siswa berkebutuhan khusus dengan desain pengembangan model 4D (Four D) termasuk kedalam kategori sangat valid dan reliabel secara teoritis sehingga layak serta dapat diuji cobakan oleh peneliti lainnya di Sanggar Kegiatan Belajar (SKB) Kota Gorontalo.

\section{Referensi}

Bachri, S. (2010). Guru dan Anak Didik Dalam Interaksi Edukatif Suatu Pendekatan teoritis Psikologis. Jakarta: PT. Rineka Cipta

Huda, M. (2013). Model-model Pengajaran dan Pembelajaran. Yogyakarta: Pustaka Pelajar

Iskandar, A. (2015). Pengembangan Perangkat Penilaian Psikomotor Di Sekolah Menengah Kejuruan. Jurnal Pendidikan

Kurniasih \& Sani. (2015). Model Pembelajaran. Yogyakarta: Kata Pena 
Mamonto, F., et al. / Jambura Physics Journal (2021) Vol. 3 (1): 54-63

Marhaeni, A.A.I.Ngr. \& Suarni, Ni Ketut. (2015). Pengaruh Model Pembelajaran Kooperatif Tipe Stad Berbantuan Media Video Animasi Terhadap Hasil Belajar IPA Dan Kreativitas Siswa SMPLB C Negeri Denpasar. Jurnal Penelitian dan Evaluasi pendidikan. 4(1)

Nuayi, A.W, Supartin, Buhungo, T.J. Stimulation of Pressure on Liquid Concept in STAD Learning Model to Improve Rational Thinking Skills and Learning Outcomes of Students. Jurnal Pendidikan Fisika Indonesia. 14 (2). 83-91

Rahayuningsih, D.I (2018). Pengembangan Media Komik Berbasis CTL Untuk Meingkatkan Hasil Belajar Siswa Sekolah Dasar Tesis. Program Pascasarjana Prodi Pendidikan Dasar, Universitas Negeri Surabaya,Retnawati, Heri. (2016). Analisis Kuantitatif Instrumen Penelitian. Yogyakarta: Parama Publishing

Santoso \& Rianto (2014). Bermain Tactile Play Terhadap Motorik Halus Anak Tunagrahita Sedang Di SDLB. Jurnal Pendidikan Khusus

Setiogihadi (2014). Penerapan Model Pembelajaran Kooperatif Tipe STAD Untuk Meningkatkan Aktivitas dan Hasil Belajar IPA Siswa Kelas VII.2 SMP Negeri 24 Palembang. Jurnal Inovasi dan Pembelajaran Fisika

Subrata (2016). Penerapan Pembelajaran Kooperatif Tipe STAD pada Materi Listrik Statis untuk Meningkatkan Aktivitas dan Hasil Belajar Peserta Didik. Jurnal Penelitian Pembelajaran Fisika

Sujadi. (2003). Metode Penelitian Pendidikan. Jakarta: Rineka cipta

Sugiyono. (2011). Metode Penelitian Kuantitatif, Kualitatif dan R\&D. Bandung: Afabeta

Thiagarajan, S. (1974). Instructional Development for Training Teachers of Exceptional Children. Washinton DC: National Center for Improvement Educational System

Trianto. (2010). Model Pembelajaran Terpadu, Konsep, Strategi dan Implementasinya. Jakarta: Bumi Aksara

Ulfah M. \& Djudin, T. (2011). Pengembangan Tes Kemampuan Berpikir Kritis Peserta Didik pada Materi Hukum Newton di SMP 